\section{BMJ Paediatrics Open}

\title{
Anaemia prevalence and its associated factors in children under 5 years in Western China: a systematic review
}

Yefan Du (D) , ${ }^{1}$ Ying Liao, ${ }^{1}$ Fangqun Leng, ${ }^{1}$ Linhua Li, ${ }^{1}$ Ruixue Ye, ${ }^{1}$ Yuping Mao, ${ }^{2}$ Hein Raat, ${ }^{3}$ Huan Zhou (iD ${ }^{1}$

\section{ABSTRACT}

Background Iron-deficiency anaemia disproportionately affects children in low-income and middle-income areas; Western China is a prime example. Given the health risks associated with childhood anaemia and the large heterogeneity of published studies on this subject, we conducted a systematic review of the evidence regarding anaemia prevalence and associated factors in children under 5 years in Western China.

Methods We searched for all relevant studies on the prevalence of iron deficiency anaemia in children under 5 years in Western China, obtaining research between 1 January 2011 and 30 June 2021, in English and Chinese from Medline, Embase, PubMed, Web of Science, CNKI, WanFang Data and VIP. Two reviewers independently screened titles and abstracts; three reviewed full texts of relevant articles for data extraction and performed quality assessments. The median prevalence was calculated on unweighted pooling, stratified by region, sex, age and ethnic group. Associated factors and a linear trend chart were conducted to identify trends and research highlights. Results Among the 55 articles included, most were cross-sectional studies (39, 70.91\%). The prevalence of anaemia in children under 5 years in Western China ranged from $3.69 \%$ to $75.74 \%$ (median $42.54 \%$ (IQR $25.62 \%-52.56 \%))$; the highest levels were in Qinghai province: $59.10 \%-75.74 \%$ (median $67.80 \%$ (IQR $64.70 \%-72.75 \%)$ ); the highest levels were reported in the subgroup of children aged 6-12 months (median 50.09\% (IQR 34.35\%-59.04\%)). Regional contexts, individual sociodemographic characteristics and feeding behaviours, and nutritional programme interventions were factors associated with anaemia prevalence.

Conclusion The prevalence of anaemia in children under 5 years in Western China is concerningly high. For this multiethnic and economically underdeveloped region, more high-quality and prospective studies are needed to inform evidence based and targeted preventive strategies to decrease the high prevalence of anaemia among young children.

${ }^{2}$ California State University Long Beach, Long Beach, California, USA

${ }^{3}$ Department of Public Health, Erasmus Medical Center, Rotterdam, Netherlands

Correspondence to Dr Huan Zhou; zhouhuan@scu. edu.cn

\section{What is known about the subject?}

Iron-deficiency anaemia disproportionately affects infants and children in low-income and middleincome areas.

- Western China, which covers $72 \%$ of China's total area and is home to $27 \%$ of the total population, is one of the least economically developed regions in the country.

- In China, four of the five provinces with the highest rates of childhood anaemia are located in Western China.

\section{What this study adds?}

In Western China, the median prevalence of anaemia in children under 5 years is $43 \%$, which is much higher than the national average.

> The highest prevalence rates $(59.1 \%-75.74 \%)$ were located in Qinghai province, and the highest levels were reported among children aged 6-24 months.

- Regional contexts, individual sociodemographic characteristics and feeding behaviours, and nutritional programme interventions play important roles in the prevalence of childhood anaemia in Western China.

causing potentially irreversible effects on cognitive and motor function even after iron supplementation. ${ }^{2-4}$ Iron-deficiency anaemia (IDA) is usually the predominant cause (more than $90 \%$ ) of early childhood anaemia in middle-income countries and LMICs, such as China. ${ }^{5}$ Despite overall improvements to child health made in China over the past three decades, the prevalence of anaemia among children younger than 5 years in western rural areas is still high. ${ }^{67}$ According to a national survey, four of the five provinces with childhood anaemia rates higher than the national average are in Western China. ${ }^{8}$ If future policies and research do not address the high prevalence of childhood anaemia 
in Western China, such health inequities will continue affecting children living in this region.

Western China includes 12 provinces (including autonomous regions and municipalities), covering about $72 \%$ of the country's area; however, only $27.2 \%$ of the country's population live in Western China. ${ }^{9}{ }^{10}$ There are 44 ethnic minority groups living in Western China, all with different customs and living habits. Understanding cultural differences between ethnic groups in Western China is crucial for children's health, as public health workers must make informed decisions on prevention efforts for these subgroups. However, most anaemia-related studies in Western China have either been conducted in specific areas that do not capture the complete diversity of the region, or have used varied research methodologies. Furthermore, the literature on childhood anaemia in Western China is dated, as the most recent reviews on this topic were conducted more than a decade ago. ${ }^{112}$

Given the health risks associated with childhood anaemia and the high heterogeneity of published studies on this topic, the objective of our study is to systematically review the medical literature on the prevalence of anaemia among children under 5 years in Western China. We aim to achieve two objectives: first, to understand the overall and subregional anaemia prevalence in Western China; and second, to identify the factors associated with childhood anaemia and the trend of anaemia prevalence in this region.

\section{METHODS}

This systematic review was conducted according to Preferred Reporting Items for Systematic Reviews and Meta-Analyses guidelines. ${ }^{13}$ The project protocol was registered with PROSPERO (ref CRD42021290915).

\section{Eligibility criteria}

Studies were eligible for inclusion only if they stated the prevalence of children under 5 years with IDA in Western China. 'Western China' is not a specific administrative division, but the region includes 12 provinces, autonomous regions and municipalities: Inner Mongolia, Guangxi, Chongqing, Sichuan, Guizhou, Yunnan, Tibet, Shaanxi, Gansu, Qinghai, Ningxia and Xinjiang (figure 1). ${ }^{14}$ As prevalence data may be sourced from different study designs, we included all relevant cross-sectional studies, randomised controlled trials (RCTs), cohort studies and published surveillance data. If results based on the same data were presented in more than one publication, results from only one publication were included.

We excluded clinical studies or case reports of children in specific hospitals or communities, and studies with sample sizes less than 50 participants, as the results of these studies are hardly representative of the regional prevalence of anaemia. We excluded studies on children in selective samples (premature, low birth weight, birth defects) or with specific types of anaemia (aplastic anaemia, thalassemia, megaloblastic anaemia).

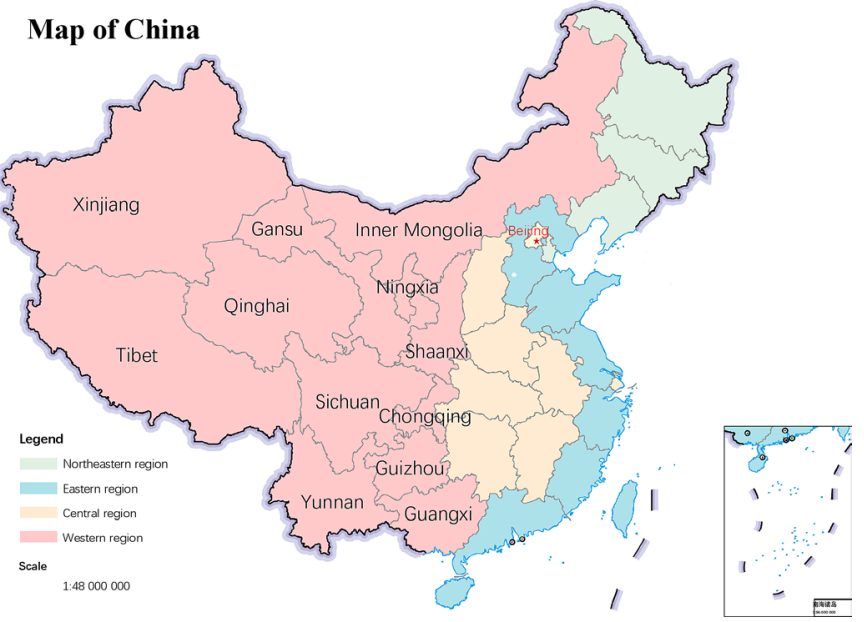

Figure 1 Location of the western region (red parts) in the map of China.

Studies with mixed samples that did not present results separately for Western children or studies that assessed IDA with unstandardised diagnostic criteria were also excluded. ${ }^{1516}$

\section{Search strategy}

Literature search strategies were developed using medical subject headings (MeSH) and text words related to childhood anaemia. The search terms for studies published in English were (anemia OR anaemia OR iron deficiency anemia OR IDA OR nutritional anemia) AND (infants OR children OR preschool) AND (China OR Chinese). The search terms for studies published in Chinese were (贫血 $\mathrm{OR}$ 缺铁性贫血 $\mathrm{OR}$ 营养性贫血) AND (婴儿 OR 婴幼儿 OR 幼儿 OR 儿童). We searched Medline (Ovid interface, 1948 onwards), Embase, PubMed, Web of Science, CNKI, WanFang Data and VIP. The literature search was limited to studies written in English and Chinese languages, published from 1 January 2011 to 30 June 2021. We carefully examined reference lists of published articles to find other related publications not identified in the database search.

\section{Selection process}

EndNote V.X9 was used to manage search results and delete duplicates. Two researchers (YL and FL) independently screened the titles and abstracts identified through the search against the inclusion criteria. As the wide range of geographic locations in Western China cannot be defined by search terms, the two researchers screened the full-text reports and determined whether studies met the inclusion criteria. Disagreements were resolved by including a third researcher (LL) to make the final decision.

\section{Assessment of methodological quality}

We used standardised forms from Joanna Briggs Institute Critical Appraisal Checklist for Studies Reporting Prevalence Data ${ }^{17}$ to determine the methodological quality of included studies. Two researchers (YL and 
FL) independently evaluated nine methodological items of study design, conduct and analysis for each included study. Each item has four choices: yes, no, unclear or not applicable. One point is assigned to a 'yes' response, and the quality score is the sum of the nine items, ranging from 0 to 9 , with a higher score indicating a lower risk of bias. ${ }^{18}$ Researchers then discussed and made a final decision, excluding studies whose scores were less than $6 .{ }^{19}$

\section{Data abstraction}

A standardised reporting form was used to extract data from each publication (online supplemental appendix table 1). The form included: study ID, first author's name, year of publication, language, study design, year of data collection, place where the study was conducted, sample size, age range of study subjects, prevalence estimates (stratified by sex, age and ethnic group) and quality score.

\section{Data synthesis}

The analysis consisted of four steps: (1) calculation of anaemia prevalence estimate in children under 5 years of age per province (distinguishing between urban and rural areas if reported), using the median percentage with IQR; (2) stratification of prevalence estimates by sex, age and ethnic group, separately; (3) collation of factors associated with childhood anaemia and (4) extraction the point estimates of prevalence (with CI) and plotting by year in different provinces of the studies. The prevalence estimates are calculated based on unweighted pooling rather than based on weighted meta-analysis methods. Data were analysed with Stata V.16.0.

\section{RESULTS}

\section{Description of studies}

As shown in figure 2, the search yielded 4815 articles (4811 from the database search, 4 from other sources), excluding 1456 duplicates. After title and abstract screening, 228 remained in the analysis. Next, 117 articles were excluded because they did not meet the inclusion criteria, and another 11 articles were removed due to duplicate data sources. After conducting quality assessments on the remaining 100 articles, 45 were excluded (online supplemental appendix table 2). In total, 55 studies (including 3 master's theses and 52 reports of original research) met the eligibility criteria and were included in this review.

Most studies were cross sectional studies ( $\mathrm{n}=39$, $70.91 \%)$, followed by prospective cohort studies $(\mathrm{n}=6$, $10.91 \%)$, surveillance data $(n=4,7.27 \%)$, RCTs $(n=3$, $5.45 \%)$ and quasi-experiments $(\mathrm{n}=3,5.45 \%)$. Twentyeight studies were descriptive and the remaining 27 were analytical (reporting associated factors analyses). The manner of reporting data varied across the studies, and we report data in their original format (online supplemental appendix table 1 ).

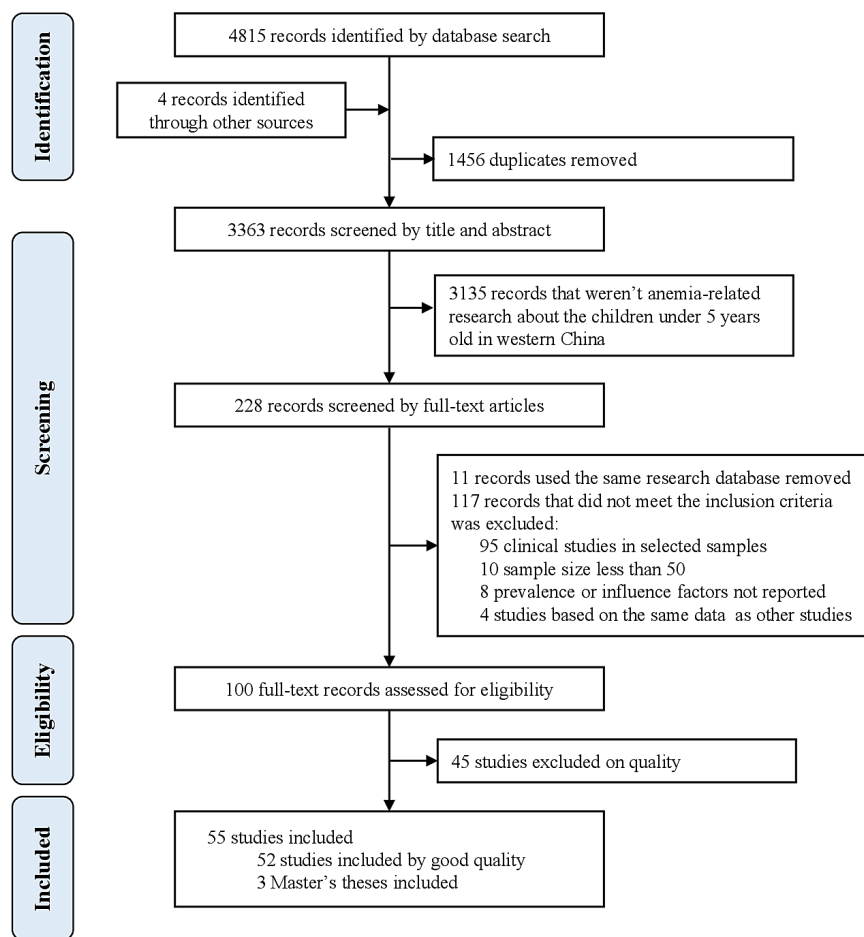

Figure 2 Study selection profile. Other resources referred to the studies scrutinised by the reference lists of published review articles, to locate additional relevant publications not identified during the database searches.

\section{Regional distribution of anaemia prevalence in child}

Overall, the reported prevalence of childhood anaemia in Western China ranged from $3.69 \%$ to $75.74 \%$ (median $42.54 \%$ (IQR 25.62\%-52.56\%)) (table 1). Studies were from six western provinces (Gansu: $n=7$; Sichuan: $n=7$; Shaanxi: n=8; Guizhou: $\mathrm{n}=7$; Yunnan: $\mathrm{n}=5$; Qinghai: $\mathrm{n}=5$ ), 5 western autonomous regions (Xinjiang: $\mathrm{n}=6$; Tibet: $\mathrm{n}=1$; Inner Mongolia: $\mathrm{n}=4$; Guangxi: $\mathrm{n}=3$; Ningxia: $\mathrm{n}=2$ ) and one western municipality (Chongqing: $\mathrm{n}=2$ ). Children in Qinghai had the highest anaemia prevalence, ranging from $59.10 \%$ to $75.74 \%$ (median $67.80 \%$ (IQR $64.70 \%-72.75 \%)$ ). One study, sampling from all 12 provinces of Western China, found that the anaemia prevalence was $49.00 \%$ a 54 .

Twenty-six articles specifically reported anaemia prevalence in rural areas, ranging from $3.69 \%$ to $72.75 \%$ (41.72\% (26.88\%-48.90\%)). Only six articles specifically reported anaemia prevalence in urban areas, which ranged from $2.29 \%$ to $44.00 \%$ (10.50\% (6.99\%23.12\%)). 5 studies compared anaemia rates between rural and urban areas, among which, two studies identified childhood anaemia prevalence was significantly higher in rural areas than in urban areas ${ }^{\mathrm{a} 2, \mathrm{a} 8}$. However, two studies in Xinjiang found the opposite result ${ }^{\text {a16, a29 }}$. Figure 3 plots the distribution of anaemia prevalence in Western China using time point data extracted from included studies. Overall, the prevalence of childhood anaemia in western regions reveals a tendency to decline slowly from 2005 to 2019. 

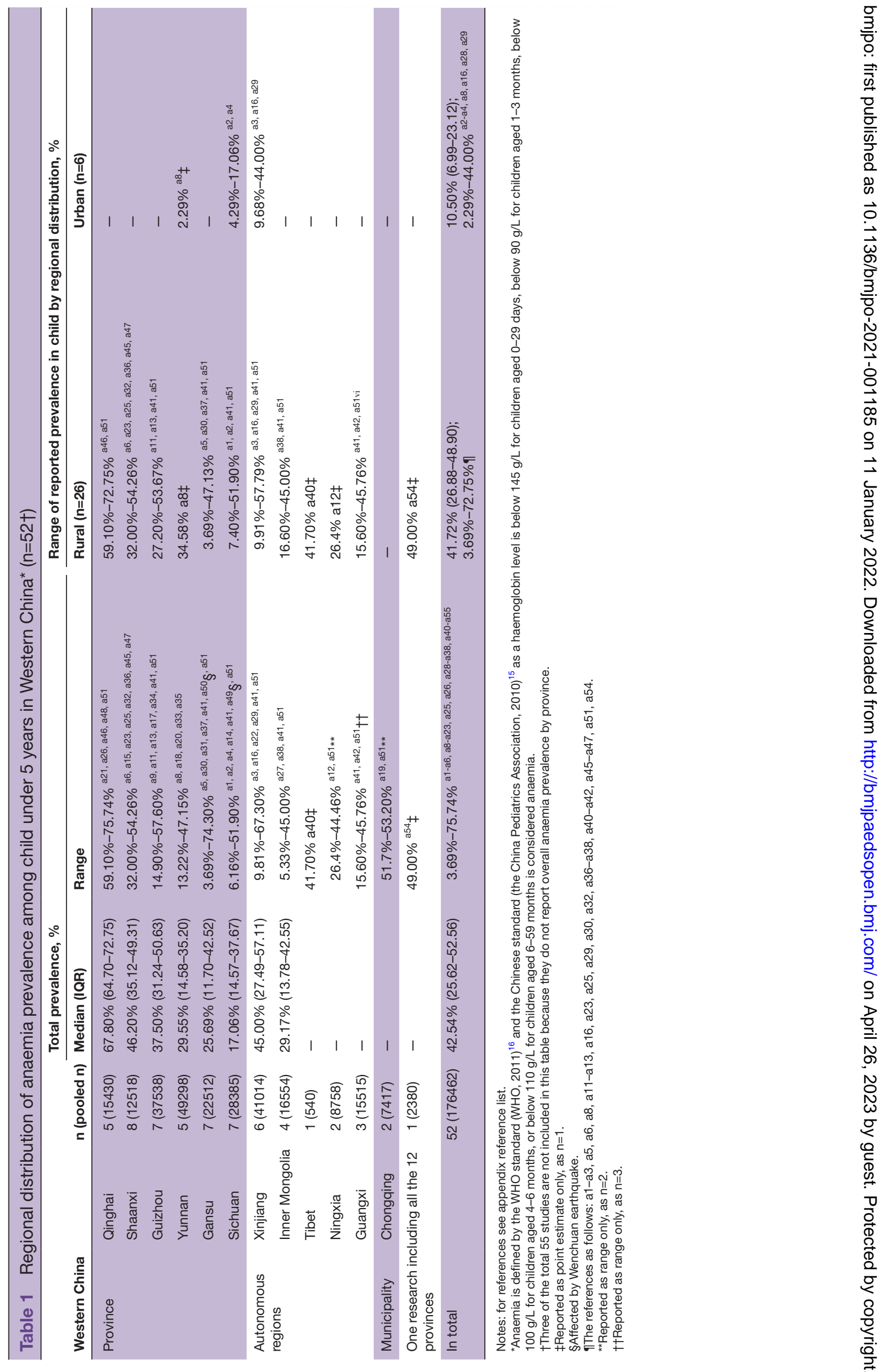


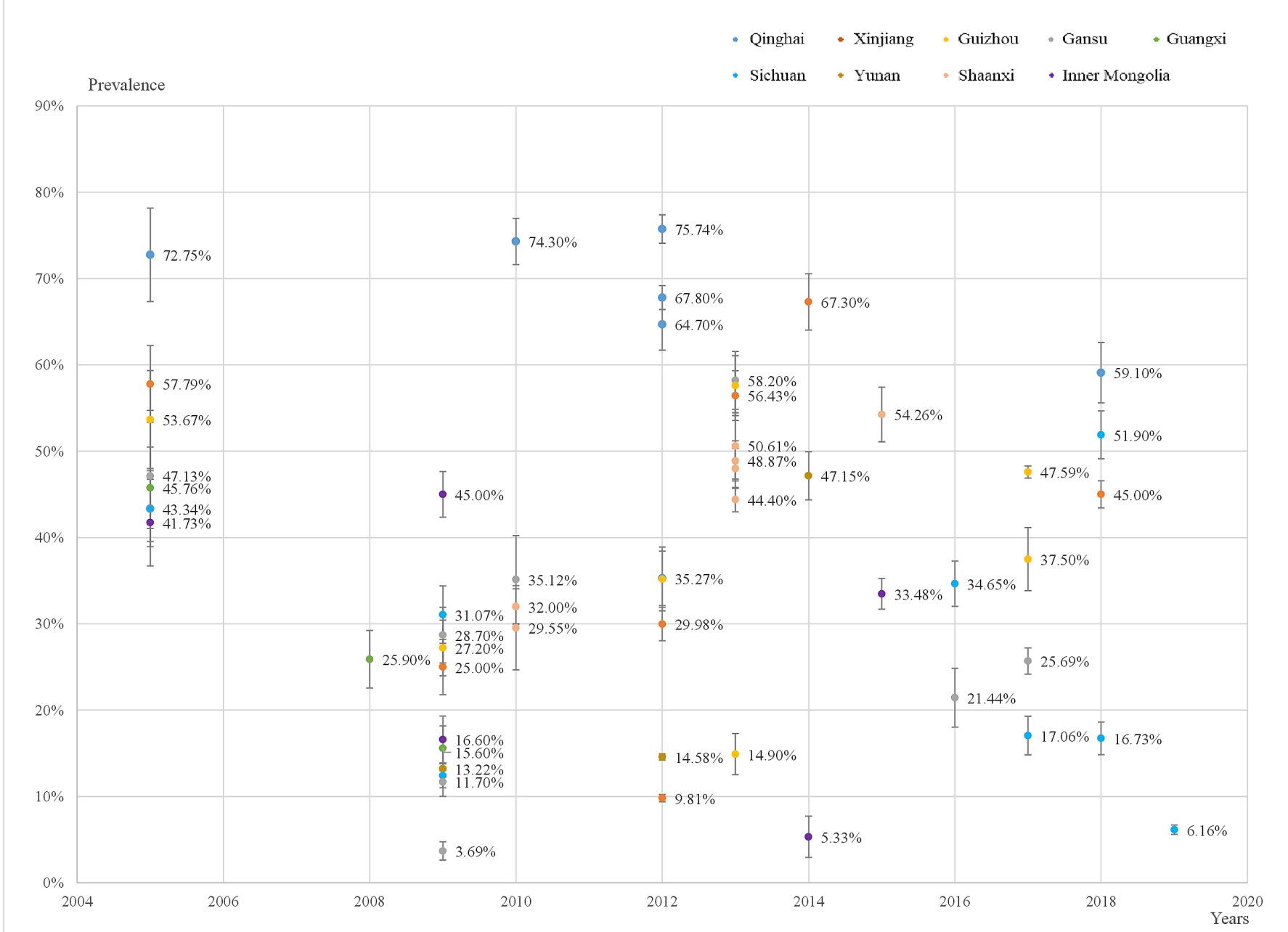

Figure 3 Point estimates of prevalence by year in nine western provinces $(n=34)$. This figure used the time of each study conducted; only when the specific time of the study was not accounted for in the article, the time of publication of the article was chosen instead.

\section{Sociodemographic distribution of anaemia prevalence in children}

Table 2 provides a sociodemographic overview of studies reporting prevalence of anaemia in children younger than 5 years in Western China. Most studies reported prevalence of anaemia in children aged 6-24 months $(\mathrm{n}=32)$. Children aged 6-12 months had a higher prevalence than other age groups $(50.09 \%$ (34.35\%$59.04 \%)$ ). The rates of anaemia in boys and girls under 5 years were similar, ranging from $3.47 \%$ to $71.10 \%$ for boys $(36.60 \%(25.68 \%-47.96 \%))$ and $3.37 \%$ to $62.90 \%$ for girls $(31.38 \%(22.62 \%-45.87 \%))$.

\section{Associated factors with childhood anaemia}

Figure 4 displays the 27 articles that conducted analysis on associated factors of childhood anaemia, controlling for confounding factors. We grouped associated factors into the seven categories (reported by descending frequency of studies): children characteristics, feeding behaviours, maternal characteristics, family characteristics, nutritional interventions, child healthcare and feeding knowledge.
Children characteristics, feeding behaviours and maternal characteristics were the most common associated factors. Regarding children characteristics, 17 articles reported associations between children age and anaemia, and most indicated that children younger than 24 months had an increased risk of anaemia ${ }^{\text {a5, a10, a11, a52. }}$ Eight articles reported association between ethnic group and childhood anaemia. Specifically, Hui, Miao and Tibetan children were at higher risk of anaemia than Han children $^{\text {a12, a13, a47 }}$. Regarding feeding behaviours, seven articles reported effects of breast feeding on anaemia: two articles reported a higher prevalence of anaemia in children who were exclusively fed formula compared with children who received a mix of formula and breastmilk ${ }^{\mathrm{a} 5}$, ${ }^{\mathrm{a} 54}$; the other five articles reported a higher prevalence of anaemia in children who were exclusively breastfed after reaching 6 months, compared with children who received mixed breastfeeding after 6 months ${ }^{\text {al1, a17, }}$ a23, a25, a39. Regarding maternal characteristics, six articles reported positive effects of maternal education on reducing childhood anaemia. Furthermore, eight articles 
Table 2 Sociodemographic distribution of anaemia prevalence among children under 5 years in Western China

\section{Prevalence \\ Median (IQR)}

Range

\begin{tabular}{|c|c|c|}
\hline \multicolumn{3}{|c|}{ Age (months) (n (pooled n)=33 (126 486)) } \\
\hline $0 \sim$ & $11.78 \%(7.90-17.87)$ & $1.70 \%-46.10 \%$ a10, a11, a35, a37, a41, a55 \\
\hline 6 & $50.09 \%(34.35-59.04)$ & $17.71 \%-72.50 \%$ a1, a5, a8, a9, a11-a13, a17-a20, a23-a26, a28, a29, a31, a35, a37, a38, a41, a44, a46, a52, a53, a55 \\
\hline $12 \sim$ & $40.81 \%(26.07-47.56)$ & $6.73 \%-69.30 \%$ a1, a2, a5, a7-a9, a13, a17-a20, a24, a26, a28, a29, a31, a33-a35, a37, a38, a41, a43, a44, a46, a52, a55 \\
\hline $24 \sim$ & $17.50 \%(10.95-24.55)$ & 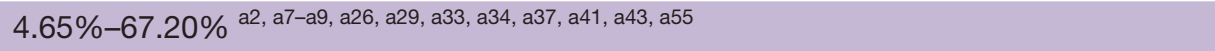 \\
\hline 36 & $12.29 \%(6.25-24.07)$ & $4.00 \%-64.70 \%$ a2, a7-a9, a33, a34, a37, a41, a43 \\
\hline $48 \sim 60$ & $12.95 \%(6.93-18.60)$ & 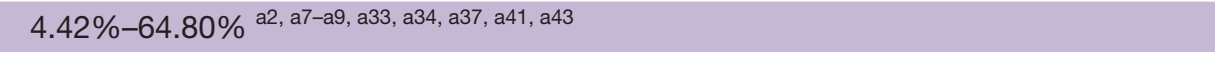 \\
\hline \multicolumn{3}{|c|}{ Sex $(n(p o o l e d n)=30(84782))$} \\
\hline Boys & $36.60 \%(25.68-47.96)$ & $3.47 \%-71.10 \%{ }^{a 1-a 3, a 5, a 6, ~ a 9, ~ a 11-a 13, ~ a 18-a 20, ~ a 22, ~ a 23, ~ a 25, ~ a 29-a 37, ~ a 40-a 42, ~ a 45, ~ a 52, ~ a 55 ~}$ \\
\hline Girls & $31.38 \%(22.62-45.87)$ & 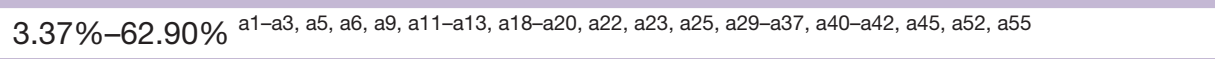 \\
\hline \multicolumn{3}{|c|}{ Ethnic group $(\mathrm{n}($ pooled $n)=9(44323))$} \\
\hline Han & - & $6.92 \%-62.70 \%$ a5, a9, a12, a21, a29, a35 \\
\hline Hui & - & $21.71 \%-53.10 \%{ }^{\text {a5, a12, a21, a29 }}$ \\
\hline Tibetan & - & $35.42 \%-78.10 \%{ }^{a 5, a 21}$ \\
\hline Miao & - & $9.2 \%-60.04 \%$ a9, a13 \\
\hline Dai & - & $23.42 \%-29.55 \%{ }^{\text {a33, a35 }}$ \\
\hline Others* & - & 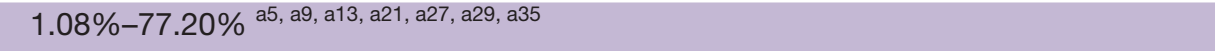 \\
\hline
\end{tabular}

${ }^{*}$ Others include Dongxiang, Dong, Shui, Maonan, Tu, Uygur, Kazak, Bulang, Jinuo, Jingpo, Deang, Achang, Dulong, Nu, Pumi, Lisu, Lahu, Hani, Va, Naxi, Molidawa, Oroqen, Ewenki and Bai minority groups.

\begin{tabular}{|c|c|c|c|c|c|c|}
\hline $\begin{array}{l}\text { Associated } \\
\text { Factors }\end{array}$ & \multicolumn{6}{|c|}{ Specific items associated with childhood anemia } \\
\hline $\begin{array}{l}\text { Children } \\
\text { characteristics }\end{array}$ & $\begin{array}{l}\text { Age in months } \\
\text { (a1, a5, a6, a9-a11, a12, } \\
\text { a13, a17, a18, a37, a38, } \\
\text { a46, a51, a54, a55) }\end{array}$ & $\begin{array}{l}\text { Ethnic group } \\
\text { (a5, a10, a12, a13, a21, } \\
\text { a38, a46, a51) }\end{array}$ & $\begin{array}{l}\text { Sex } \\
\text { (a18, a40, a42, a51, a54, } \\
\text { a55) }\end{array}$ & $\begin{array}{l}\text { Low birth weight } \\
\text { (a13, a53) }\end{array}$ & $\begin{array}{l}\text { Premature } \\
(\mathrm{a} 11, \mathrm{a} 42)\end{array}$ & $\begin{array}{l}\text { Illness in the past two } \\
\text { weeks } \\
\text { (a25) }\end{array}$ \\
\hline $\begin{array}{l}\text { Feeding } \\
\text { behaviors }\end{array}$ & $\begin{array}{l}\text { Breastfeeding status } \\
\text { (a5, a11, a17, a23, a25, } \\
\text { a38, a53) }\end{array}$ & $\begin{array}{l}\text { Duration of continuous } \\
\text { breastfeeding } \\
\text { (a1, a9, a25, a42) }\end{array}$ & $\begin{array}{l}\text { First time of introducing } \\
\text { supplementary food } \\
(\mathrm{a} 9, \mathrm{a} 13, \mathrm{a} 25)\end{array}$ & $\begin{array}{l}\text { Supplementary food } \\
\text { diversity } \\
(\text { a6, a1 1, a13, a21, a23, } \\
\text { a46, a55) }\end{array}$ & $\begin{array}{l}\text { Frequency of } \\
\text { supplementary food } \\
\text { addition } \\
(\mathrm{a} 23, \mathrm{a38})\end{array}$ & $\begin{array}{l}\text { First bite of food after } \\
\text { birth } \\
\text { (a42) }\end{array}$ \\
\hline $\begin{array}{l}\text { Maternal } \\
\text { characteristics }\end{array}$ & $\begin{array}{l}\text { Education } \\
\text { (a1, a38, a40, a42, a53, } \\
\text { a54) }\end{array}$ & $\begin{array}{l}\text { Gestational anemia } \\
\text { (a10, a13, a51, a55) }\end{array}$ & $\begin{array}{l}\text { Age } \\
(\mathrm{a} 6, \mathrm{a} 40, \mathrm{a} 53)\end{array}$ & $\begin{array}{l}\text { Occupation } \\
\text { (a13, a18) }\end{array}$ & $\begin{array}{l}\text { Iron supplementation } \\
\text { during pregnancy } \\
\text { (a11) }\end{array}$ & \\
\hline $\begin{array}{l}\text { Family } \\
\text { characteristics }\end{array}$ & $\begin{array}{l}\text { Annual household } \\
\text { income per capita } \\
\text { (a11, a13, a18, a53, a54) }\end{array}$ & $\begin{array}{l}\text { Household environment } \\
\text { (a21) }\end{array}$ & $\begin{array}{l}\text { Family size } \\
\text { (a51, a53) }\end{array}$ & $\begin{array}{l}\text { Residence area } \\
(\mathrm{a} 13, \mathrm{a} 51)\end{array}$ & $\begin{array}{l}\text { Primary caregiver role } \\
\text { (a13) }\end{array}$ & \\
\hline $\begin{array}{l}\text { Child } \\
\text { health care }\end{array}$ & $\begin{array}{l}\text { Medical Examination } \\
(\mathrm{a} 9, \mathrm{a} 10)\end{array}$ & $\begin{array}{l}\text { Vaccination } \\
\text { (a10) }\end{array}$ & & & & \\
\hline $\begin{array}{l}\text { Feeding } \\
\text { knowledge }\end{array}$ & $\begin{array}{l}\text { Feeding knowledge } \\
(\mathrm{a} 1, \mathrm{a} 5)\end{array}$ & & & & & \\
\hline
\end{tabular}

Figure 4 Frequency of studies on influencing factors of anaemia in children under 5 years in Western China $(n=27)$. The darker the colour, the more research. 'Ying Yang Bao' is a free nutrition package provided by the Chinese government for children aged 6-24 months in the poor rural areas. 
reported the effects of Ying Yang Bao (YYB, a nutrition pack ${ }^{20}$ on anaemia, all reporting that supplemental feeding with YYB has a significant protective effect on the prevention of childhood anaemia.

\section{DISCUSSION}

In this review, we report a descriptive synthesis of studies that investigate anaemia in children under 5 years in Western China. Our findings highlight a higher prevalence of childhood anaemia in Western China (around $43 \%)$ than all of China (12\%). ${ }^{8}$ Despite recent efforts to decrease the prevalence of childhood anaemia in China, childhood anaemia remains a severe public health challenge in Western China that deserves extensive attention (WHO, 2011). ${ }^{16}$ Regional contexts, individual sociodemographic characteristics and feeding behaviours, as well as nutritional programme interventions play important roles in the prevalence of childhood anaemia in Western China.

We found that childhood anaemia is more prevalent in western regions of China than in other regions, which is consistent with previous research. ${ }^{6}$ The division of eastern, central and western regions of China is based on levels of economic development, policy implementation and geographical locations. The western region is less economically developed than the other regions, ${ }^{21}$ contributing 20.7\% of the National Economic Gross Domestic Product in 2019, compared with the eastern and central regions' contributions of $51.6 \%$ and $27.2 \%$, respectively. ${ }^{21}$ Moreover, anaemia prevalence varies widely within the western region; for example, the highest reported anaemia prevalence was in Qinghai while the lowest prevalence was in Sichuan.

Children belonging to an ethnic minority group showed higher anaemia rates than Han children in Western China. The western region is multiethnic, and the minority population in Western China accounts for about $71 \%$ of the national minority population. Moreover, the geographical area populated by minority groups accounts for about $90 \%$ of the total area in the west. ${ }^{22}$ Several studies on the prevalence of anaemia among children from different ethnic groups in the western region were included in this review, among which relatively more studies focus on the Hui, Tibetan, Miao and Dai minority groups. Those studies reported that Hui, Tibetan and Miao children had significantly higher prevalence of anaemia than Han children. ${ }^{23-25}$ Moreover, 319 of the 592 national poverty-stricken counties in China ${ }^{26}$ are located where western minority groups live, thus indicating that the highest poverty rates affect minority populations. Because intergenerational transmission of poverty happens in the typical cycle of poverty-malnutritionpoverty in developing countries, ${ }^{27}$ researchers and policymakers must be aware of the high prevalence of anaemia among children in western minority groups.

In summarising the results of the studies, the prevalence of anaemia is highest among children aged 6-24 months, which is consistent with findings from the WHO. ${ }^{28}$ The prevalence of anaemia is higher in children who continue exclusive breastfeeding over 6 months, compared with those who have timely supplementation. This may be explained by children's changing nutritional needs at different developmental stages. If caregivers do not add adequate or appropriate complementary food in a timely manner, children aged 6-24 months are at greater risk of anaemia. ${ }^{29}$ To improve the nutrition and health status and the prevalence of IDA among children aged 6-24 months in poor areas, in October 2012, the Chinese government launched a major primary healthcare project to prevent malnutrition and anaemia. ${ }^{30-32}$ The project provides free, iron-rich nutrition packages to caregivers and promotes scientific knowledge and proper child feeding skills. ${ }^{20}$ In 2013, 187 counties in Western China were covered by this project, ${ }^{33}$ and between 2012 and 2017, the national anaemia rate decreased from $32.9 \%$ to $17.6 \% .^{34}$ These results are illustrated in figure 3 , which shows the tendency that prevalence of childhood anaemia in the western region has been decreasing by year.

To our knowledge, this is one of few reviews in recent years that focuses on anaemia in children under 5 years in Western China. Our study highlights several limitations of the literature in this field. First, during our database search, we identified fewer relevant studies for Western China compared with the rest of China (228 vs 3363). It is also worth noting that there is a large research gap in childhood anaemia research between different provinces and minority groups within the western region. Second, there were only two RCTs among all included studies (2 vs 55). Most included articles are cross-sectional studies, which do not explore the causality of anaemia or propose active and effective measures. When measures were suggested, they tended to be general health advisories without a targeted audience, making them less useful for policy changes and interventions. ${ }^{3536}$ Third, the uneven distribution of study designs and quality of studies contributed to a high heterogeneity of studies. More than $40 \%$ of the studies that met our inclusion criteria were excluded due to poor research quality. The quality evaluation scores of articles in Chinese are mostly lower than those of articles in English. The above limitations regarding existing literature led to several limitations of our systematic review. However, one major limitation of this review is the absence of a meta-analysis. We could not perform a meta-analysis due to the large methodological heterogeneity of the included studies. Additionally, we were unable to produce pooled regional or overall prevalence estimates; therefore, only median and quartiles are reported in this review.

\section{CONCLUSIONS}

This study provides a holistic review of preschool children's anaemia research in Western China. The prevalence of anaemia in children under 5 years in Western 
China is still relatively high, despite recent efforts to decrease anaemia prevalence. For such a multiethnic and poor region, interventions must be tailored to local ethnic and regional characteristics. In light of our findings, more high-quality and prospective studies are urgently needed to inform targeted and evidence-based preventive strategies to identify causes of the high prevalence of childhood anaemia in remote and poor areas, as well as to provide timely public health service to economically disadvantaged populations.

Acknowledgements The authors would like to thank the West China School of Public Health at Sichuan University and all the research teams focused on western China for their hard work and dedication.

\section{Collaborators No collaborators in this review.}

Contributors $\mathrm{HZ}$ formulated the research questions and designed the study, served as the guarantor; $\mathrm{YD}, \mathrm{HZ}$ and $\mathrm{RY}$ designed the search strategy. YD, YL and FL conducted the search, retrieved publications, screened full text and assessed the quality of the articles. YD wrote the draft of the manuscript, with specific sections collaborated by YL and FL. YL and YD produced all figures and tables. $\mathrm{HZ}$, LL, YM and HR reviewed the manuscript. All authors critically revised the manuscript and agreed to the published version of the manuscript.

Funding This research was funded by the National Natural Science Foundation of China (NSFC), grant no. 71874114

Map disclaimer The inclusion of any map (including the depiction of any boundaries therein), or of any geographic or locational reference, does not imply the expression of any opinion whatsoever on the part of BMJ concerning the legal status of any country, territory, jurisdiction or area or of its authorities. Any such expression remains solely that of the relevant source and is not endorsed by BMJ. Maps are provided without any warranty of any kind, either express or implied.

Competing interests No, there are no competing interests.

Patient consent for publication Not applicable.

Provenance and peer review Commissioned; externally peer reviewed.

Data availability statement Data sharing not applicable as no datasets generated and/or analysed for this study. Not applicable.

Supplemental material This content has been supplied by the author(s). It has not been vetted by BMJ Publishing Group Limited (BMJ) and may not have been peer-reviewed. Any opinions or recommendations discussed are solely those of the author(s) and are not endorsed by BMJ. BMJ disclaims all liability and responsibility arising from any reliance placed on the content. Where the content includes any translated material, BMJ does not warrant the accuracy and reliability of the translations (including but not limited to local regulations, clinical guidelines, terminology, drug names and drug dosages), and is not responsible for any error and/or omissions arising from translation and adaptation or otherwise.

Open access This is an open access article distributed in accordance with the Creative Commons Attribution Non Commercial (CC BY-NC 4.0) license, which permits others to distribute, remix, adapt, build upon this work non-commercially, and license their derivative works on different terms, provided the original work is properly cited, appropriate credit is given, any changes made indicated, and the use is non-commercial. See: http://creativecommons.org/licenses/by-nc/4.0/.

ORCID iDs

Yefan Du http://orcid.org/0000-0002-8712-5695

Huan Zhou http://orcid.org/0000-0002-6709-5134

\section{REFERENCES}

1 Yu D, Liu A, Yu W, et al. [Status of malnutrition and its influencing factors in children under 5 years of age in poor areas of China in 2009]. Wei Sheng Yan Jiu 2011;40:714-8.

2 Lozoff B, Beard J, Connor J, et al. Long-Lasting neural and behavioral effects of iron deficiency in infancy. Nutr Rev 2006;64:34-43.

3 Low M, Farrell A, Biggs B-A, et al. Effects of daily iron supplementation in primary-school-aged children: systematic review and meta-analysis of randomized controlled trials. CMAJ 2013;185:E791-802.

4 Sundararajan S, Rabe H. Prevention of iron deficiency anemia in infants and toddlers. Pediatr Res 2021:89:63-73.

$5 \mathrm{Ji} \mathrm{C}$. Child and adolescent hygiene. Beijing: People's Health Publishing House, 2012: 140-2.

6 Xin Q-Q, Chen B-W, Yin D-L, et al. Prevalence of anemia and its risk factors among children under 36 months old in China. J Trop Pediatr 2017;63:36-42.

7 Wang L, Sun Y, Liu B, et al. Is Infant/Toddler anemia a problem across rural China? A mixed-methods analysis. Int $J$ Environ Res Public Health 2018;15. doi:10.3390/ijerph15091825. [Epub ahead of print: 2308 2018].

8 Fang H-Y, D-M Y, Guo Q-Y. Anemia prevalence of among 0-5 years old children in China, 2013. Chinese Journal of Public Health 2018;34:1654-7.

9 Statistics NBo. Sichuan: study on human resource development and utilization in Western region, 2004. Available: http://www.stats.gov. cn/ztjc/ztfx/fxbg/200407/t20040714_14766.html [Accessed 8 Apr 2021].

10 Statistics NBo. The seventh national census bulletin (No. 3), 2021. Available: http://www.stats.gov.cn/tisj/tigb/rkpcgb/qgrkpcgb/ 202106/t20210628_1818822.html [Accessed 8 Apr 2021].

11 Yan $\mathrm{H}$, Wang Q, Li Q. A preliminary analysis of malnutrition among children under 3 years of age in Western China in 2005. 2006 annual scientific meeting of Chinese Academy of medical sciences and. Beijing: China Union Medical University, 2006.

12 Zhang A. The study on anemia of children among 6 35 months in 46 counties of midwestern China and meta analysis on the effect of daily iron supplementation and Weekly iron supplementation. Peking University Health Science Center, 2009.

13 Moher D, Liberati A, Tetzlaff J, et al. Preferred reporting items for systematic reviews and meta-analyses: the PRISMA statement. Open Med 2009;3:e123-30.

14 Statistics NBo. Statistical system and classification standards, 2020. Available: http://www.stats.gov.cn/tjzs/cjwtjd/201308/t20130829 74318.html [Accessed 8 Apr 2021].

15 Zheng J, Wu H. Diagnosis and treatment of child nutritional anemia. Chinese Community Doctors 2010;12:3-5.

16 World Health Organization. Haemoglobin concentrations for the diagnosis of anaemia and assessment of severity. Geneva: World Health Organization, 2011. Available: https://www.who.int/vmnis/ indicators/haemoglobin.pdf?ua $=1$ [Accessed 8 Apr 2021].

17 Munn Z, Moola S, Lisy K. Chapter 5: Systematic reviews of prevalence and incidence. In: Aromataris E ZM, ed. JBI manual for evidence synthesis. JBI, 2021.

18 Luo W, Zhong B-L, Chiu HF-K. Prevalence of depressive symptoms among Chinese university students amid the COVID-19 pandemic: a systematic review and meta-analysis. Epidemiol Psychiatr Sci 2021;30:e31.

19 Ofori-Asenso R, Chin KL, Mazidi M, et al. Global incidence of frailty and Prefrailty among community-dwelling older adults: a systematic review and meta-analysis. JAMA Netw Open 2019;2:e198398.

20 Dong C, Ge P, Ren X, et al. Prospective study on the effectiveness of complementary food supplements on improving status of elder infants and young children in the areas affected by Wenchuan earthquake. PLoS One 2013;8:e72711.

21 Statistics NBo. Statistical Bulletin on National Economic and Social Development of the People's Republic of China 2019, 2020. Available: http://www.stats.gov.cn/tjsj/zxfb/202002/t20200228_ 1728913.html [Accessed 8 Apr 2021].

22 Deng Z, Gao W. Analysis of the changes of minority population in Western China: based on the data from China' $\mathrm{S}$ sixth census in 2010. Guangxi Ethnic Studies 2013;3:57-65.

23 Yu C, Ban W, Xie L. Prevalence and influence factors of iron deficiency anemia among 6-23 months old children in Qiannan area of Guizhou Province. Chinese Journal of Public Health 2018;34:812-6.

$24 \mathrm{LiX}$, Sun C, Liu Y Analysis of nutritional status and influencing factors of infants aged $6 \sim 24$ months in poor areas of Ningxia. Maternal \& Child Health Care of China 2018;33:5560-2.

25 Huang $\mathrm{Y}$, Wang L, Huo J, et al. Prevalence and causes of anaemia in children aged 6-23 months in rural Qinghai, China: findings from a cross-sectional study. BMJ Open 2019;9:e031021.

26 Ding Sai HS, Gustavsson B. A comparison of urban and rural poverty between Han Chinese and ethnic minorities in Western ethnic areas. Journal of Southwest University for Nationalities 2016;37:154-62.

27 Li X-q SC-t, Liu Y, et al. Analysis of the nutritional status of infants and young children aged 6-24 months in poor areas of Ningxia and 
the factors affecting them. Maternal \& Child Health Care of China 2018;33:5560-2.

28 Organization WH. Nutritional anaemias: tools for effective prevention and control, 2017. Available: https://www.who.int/publications/i/ item/9789241513067 [Accessed 14 Sep 2021].

29 Fang J, Luo J, Liao K. Analysis of anemia among children aged 6-24 months in poor rural areas of Hunan Province. Chin $J$ Child Health Care 2017;25:824-6.

30 Huo J, Sun J, Fang Z, et al. Effect of home-based complementary food fortification on prevalence of anemia among infants and young children aged 6 to 23 months in poor rural regions of China. Food Nutr Bull 2015;36:405-14.

31 Smith G. Micronutrient fortification of food: issues for Asia. J Nutr Sci Vitaminol 2015;61 Suppl:S183-5.

32 Wang J, Chang S, Zhao L, et al. Effectiveness of communitybased complementary food supplement (Yingyangbao) distribution in children aged 6-23 months in poor areas in China. PLoS One 2017;12:e0174302.

33 China HaFPCo. The 2013 nutrition improvement project for children in poor areas program was issued 2013. Available: http://www. gov.cn/gzdt/2013-11/29/content_2538706.htm [Accessed 15 Aug 2021].

34 Yang Z, Zhang $\mathrm{H}$, Wang $\mathrm{Y}$. Strategies and measures of nutrition improvement for children under 5 years in China. Journal of Food Science and Technology 2020;38:8-13.

35 G-m L, Ge F, Fang P. Surveillance of nutritional status of children under 5 year-old in two counties, Xinjiang. Endemic Diseases Bulletin(china) 2018;33:65-7.

36 Gao W, Yan H, Wang D, et al. Severity of anemia among children under 36 months old in rural Western China. PLoS One 2013;8:e62883. 